\title{
Latitudinal variation in shell growth patterns of Phacosoma japonicum (Bivalvia: Veneridae) from the Japanese coast
}

\author{
Kazushige Tanabe ${ }^{1}$, Tadamichi $\mathrm{Oba}^{2}$ \\ ${ }^{1}$ Geological Institute, University of Tokyo, Tokyo 113, Japan \\ ${ }^{2}$ Department of Geology, College of Liberal Arts, Kanazawa University, Kanazawa 920, Japan
}

\begin{abstract}
Shell growth patterns of Phacosoma japonicum (Reeve) were examined from 5 locations around the Japanese coast, using annual increments within the internal shell sequence. Recognition of annual increments is based on the presence of growth cessation marks or biochecks (= slow growth bands), both of which were formed by winter of each year. Northern individuals generally possess a smaller growth parameter in von Bertalanffy equations and a longer life span than southern ones. Toward the south, the number of microincrements within each annual increment tends to increase, whereas the mean microincrement width gradually decreases. Winter growth cessation marks are especially conspicuous in individuals from Seto Inland Sea and northward. The range of temperatures calculated from ${ }^{18} \mathrm{O} /{ }^{16} \mathrm{O}$ ratios of 2 selected specimens correlates well with the season of phytoplankton abundance in the habitats. These lines of evidence strongly suggest that the north-south cline detected results mainly from the difference in the length of the growing season among local populations, depending on both temperature and trophic resource seasonality.
\end{abstract}

\section{INTRODUCTION}

Periodic structures of different magnitudes are commonly observed within the marginally growing skeletons of invertebrates. Of these, annual increments may be most important for life history analysis of living organisms. Annual layering is actually present in the majority of Recent bivalves studied in detail (Lutz \& Rhoads 1980), and has been utilized in age and growth rate determinations of local populations (Mason 1957, Hallam 1967, Jones et al. 1978, Seed \& Brown 1978, Bachelet 1980, Jones 1980, Tanabe 1988) and in documenting conspecific variation of shell growth patterns (Hall et al. 1974, Beukema \& Meehan 1985, Harrington 1987).

The venerid Phacosoma japonicum (Reeve) treated in this paper also preserves large-scale repeating structures in the outer aragonite layer of the shells. This species is common in the sandy-to-muddy sediments of intertidal to lower subtidal environments, distributed on the coasts of Japan, Korea and China (Habe 1977). Recent sclerochronological analysis of marked and recovered individuals from the coast of the Seto Inland Sea demonstrated that the large-scale repeating layers in this species can be used as annual increments for age and growth rate determinations (Tanabe 1988). Using this approach, this paper considers the latitudinal variation of shell growth patterns in this species over a wide geographic range around the Japanese Islands, and discusses its ecological implications.

\section{MATERIAL AND METHODS}

Samples of Phacosoma japonicum were collected from 5 locations along the Japanese coast: (1) subtidal sand flat of Wakkanai Port, northern Hokkaido, (2) subtidal sand flat of the Kamiiso Coast, Hakodate Bay, southern Hokkaido, (3) intertidal sand flat of the Kaneda Coast, Kisarazu, Tokyo Bay, central Honshu, (4) intertidal sandy mud flat of the Kawarazu Shore, Toyo, Seto Inland Sea, Shikoku, and (5) intertidal sandy mud flat of the Arao Coast, Ariake Bay, Kyushu (Fig. 1). The Wakkanai coast is presumed to be at the northern limit of the zoogeographic range of this species. Sea-surface temperature tends to decrease with increasing latitude (Fig. 2). The range of annual temperature variation in the northern locations is much 


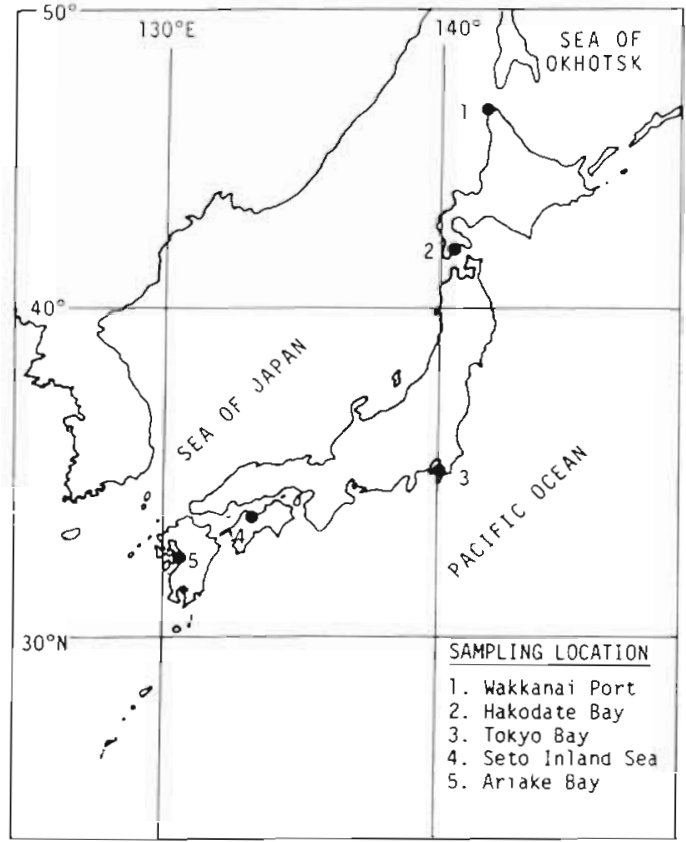

Fig. 1. Sampling locations of Phacosoma japonicum

larger than that in the southern locations. This is largely a reflection of the flow patterns of the warm Kuroshio current from the south and the cold Oyashio current from the north. Very low winter temperatures in the Wakkanai water result from influx of floating ice from the Sea of Okhotsk.

After having removed soft tissues from the shells, a single valve for each specimen was sectioned from umbo to ventral margin along the maximum shell growth axis with the aid of an Isomet low speed saw (Buehler Co.). Following the methods described in Tanabe (1988), the sectioned surface was polished, etched, and then acetate peels were prepared for every specimen. The etched surface of several specimens was coated with platinum, and the microtexture was observed under the SEM (Hitachi S-430). Measurements of the internal increment sequence were made on the peeled specimens using a profile projector (Nikon Co., model V-16), attached to a digital micrometer (accuracy $\pm 1 \mu \mathrm{m}$ ) (magnifications $\times 200$ ). Recognition of annual increments in the shell crosssections is based on the criteria described in Tanabe (1988). The annual increments are distinguishable by gradual narrowing of microincrements in their marginal portion and the presence of a clear growth cessation mark at the boundary of 2 annual increments (Fig. 3). In the population on the Kawarazu Shore, the growth cessation mark is formed annually during winter (November-February), and is expressed by discontinuity (break) in microincrement growth (Tanabe 1988). Winter formation of growth cessation

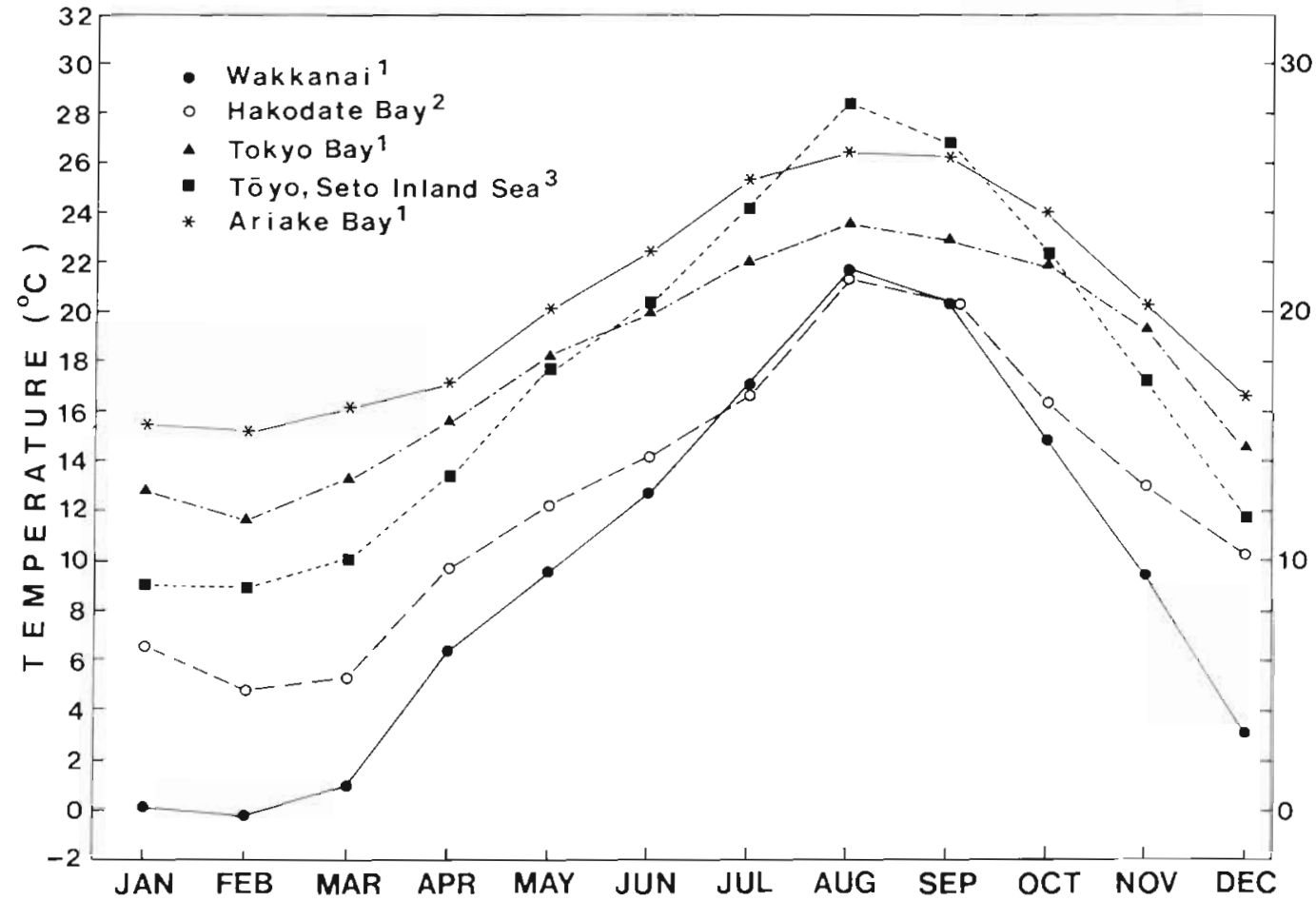

Fig. 2. Monthly mean water temperatures near the sampling locations. Data sources: (1) Oceanographic observations by the Japan Meteorological Agency in 1985 (Japan Meteorological Agency 1986), (2) unpubl. data of the marine biological station of the Hokkaido University of Education during 1979-1980; (3) unpubl. data of the Ehime Prefectural fisheries experiment station in 

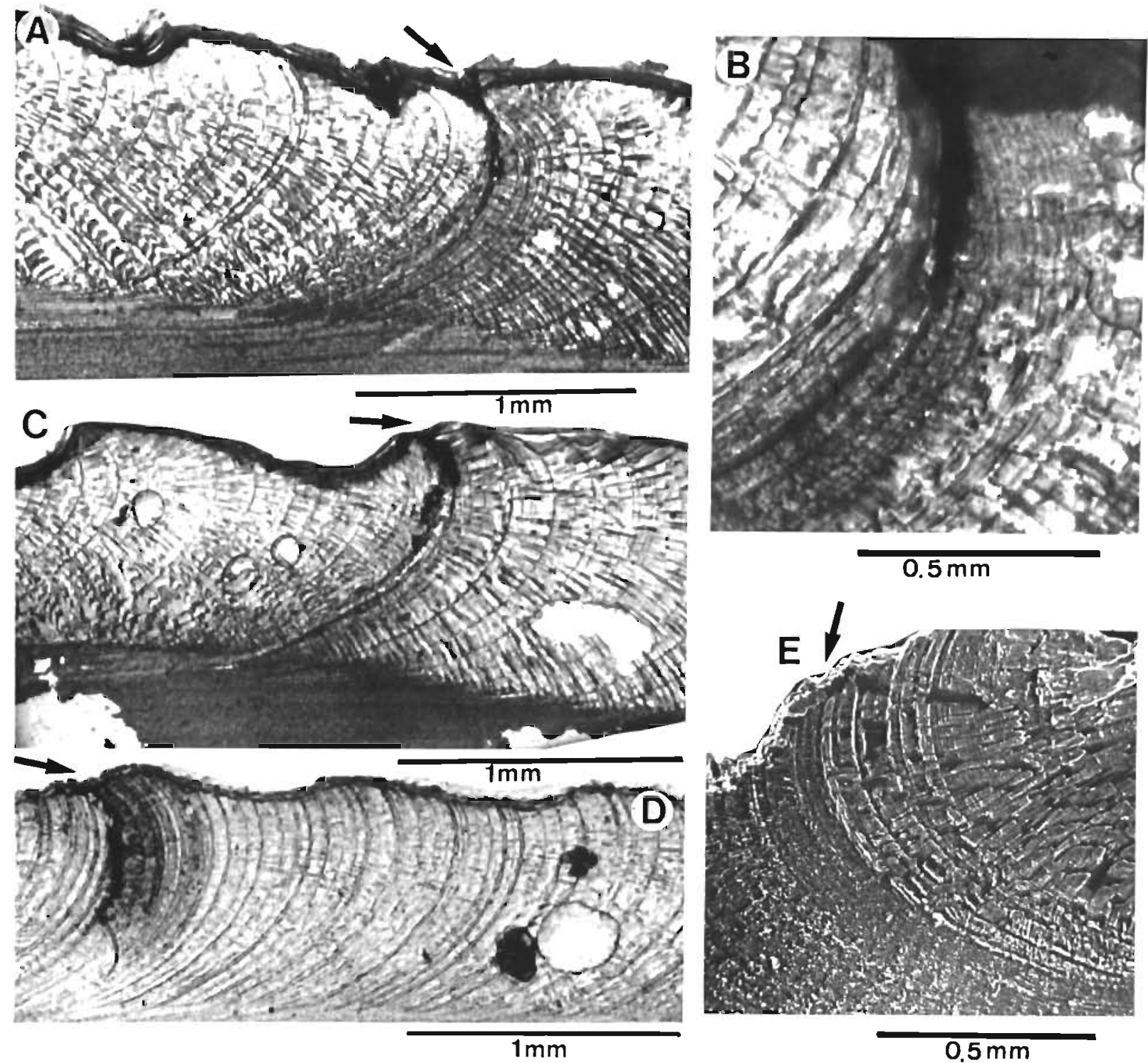

Fig. 3. Phacosoma japonicum. Boundary (arrows) between 2 annual increments for specimens from different locations. (A \& B) Growth cessation mark between 4 th and 5 th annual increments in a specimen from Wakkani Port. (C) Growth cessation mark between 3rd and 4 th annual increments in a specimen from Kamiiso Coast, Hakodate Bay. (D) Growth cessation mark between 3rd and 4th annual increments in a specimen from Kaneda Coast, Tokyo Bay. (E) Biocheck between 5th and 6th annual increments in a specimen from Arao Coast, Ariake Bay

marks is strongly suggested for specimens from other localities by the microincrement sequence near the ventral shell margin and its comparison with sampling date.

Shell height from umbo to the ventral margin of each annual increment was first measured in each specimen of Phacosoma japonicum. Average shell heights for each annual increment were used to describe shell growth patterns at the 5 sample sites examined. Shell growth of each population was modeled by fitting the von Bertalanffy equation (von Bertalanffy 1938) to the age/mean shell height data:

$$
H_{t}=H_{\infty}\left(1-\mathrm{e}^{-K\left(t-t_{0}\right)}\right)
$$

where $H_{t}=$ shell height of an animal at time $t_{i} H_{x}=$ maximum asymptotic shell height; $K=$ a growth constant; and $t_{0}=$ theoretical time when $H_{t}=0$. We also computed Gallucci \& Quinn's (1979) growth parameter $\omega\left(\omega=K \cdot H_{\infty}\right)$ for each sample.

Shells of 2 specimens (nos. K72 and W29 from Toyo and Wakkanai areas) were used in stable isotopic analysis. In this analysis, small amounts of powdered calcium carbonate sample (ca $0.1 \mathrm{mg}$ each) were collected in a series by drilling the outer prismatic layer 
parallel to the shell increments from umbo to ventral margin. Each sample was reacted in $100 \%$ phosphorous acid at $60^{\circ} \mathrm{C}$, and the oxygen and carbon isotopic compositions of the evolved carbon dioxide gas were determined on a Finnigan MAT 251 mass spectrometer. Isotopic values are expressed relative to the carbon dioxide gas derived from the Pee Dee Belemnite (PDB) standard carbonate powder (Epstein et al. 1953) in conventional delta notation. Analytical precision was less than $0.03 \%$.

\section{RESULTS}

\section{Growth parameters}

A plot of mean shell height data versus annual increments for each site provides a generalized growth curve (Fig. 4). In every sample the growth curve predicts a decrease of the specific growth rate as the shell height approaches the upper limit. Maximum attainable shell size and specific growth rate both seem to be markedly different among the 5 sites. The shell growth curves for the 5 sites, based on annual increments, are nicely fit by the von Bertalanffy equation, although the actual growth patterns of living individuals cannot be approximated by a simple curve owing to the annual fluctuation in growth rates (Tanabe 1988). Both the growth constant $K$ and the $\omega$ parameter of Gallucci \& Quinn (1979) systematically decrease to the north, although no latitudinal trend was detected for the maximum asymptotic shell height $\left(H_{\infty}\right)$ (Table 1$)$. The Arao population shows the largest variation in shell height at a given age.

\section{Microincrement growth}

Ontogenetic changes of the microincrement growth patterns in the present species can be expressed by plotting their number and mean width in relation to annual increments (Figs. 5 and 6). In every sample,

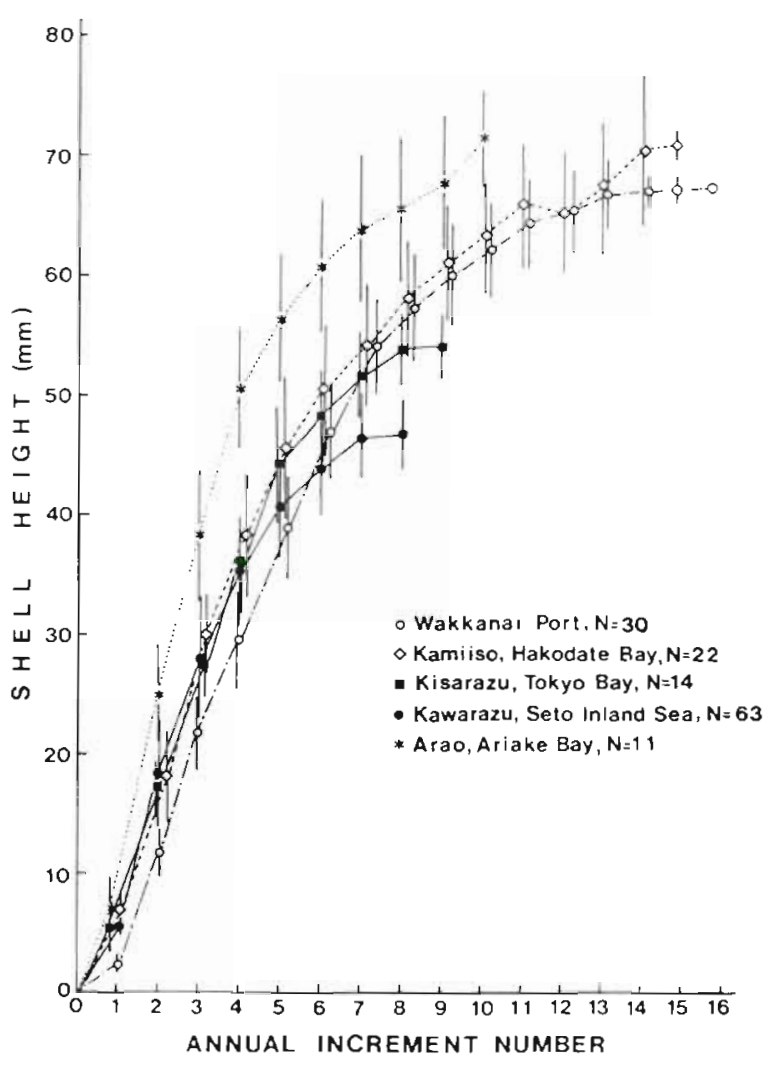

Fig. 4. Phacosoma japonicum. Generalized growth curves for samples from different locations. Sample mean and range of standard deviation are indicated for each sample

both number and mean width of yearly formed microincrements tend to decrease with age. At the same age, the number of annually formed microincrements in the southern individuals is much larger than that in the northern individuals. In contrast, the mean growth rate at a given age tends to increase towards the north.

\section{Oxygen isotope ratios}

$\delta^{18} \mathrm{O}$ profiles in the 2 specimens from the Wakkanai and Kawarazu areas are shown in Fig. 7. A clear annual

Table 1. Phacosoma japonicum. Growth parameters of von Bertalanffy equations for samples from Japanese coast. Age/mean shell height data shown in Fig. 4 are used in this calculation. $H x$ : maximum asymptotic shell height, $K$ : growth constant, $\omega$ : growth parameter, $t_{0}$ : theoretical time when shell height $\left(H_{t}\right)$ is zero

\begin{tabular}{|c|c|c|c|c|c|}
\hline Locality & $\begin{array}{c}\text { Mean annual } \\
\left.\text { temp. } 1^{\circ} \mathrm{C}\right)\end{array}$ & $\mathrm{H} x(\mathrm{~mm})$ & $K$ & (1) & $t_{0}(y r)$ \\
\hline Wakkanai Port & 9.7 & 78.95 & 0.159 & 12.58 & -0.205 \\
\hline Hakodate Bay & 12.3 & 74.46 & 0.203 & 15.11 & -0.471 \\
\hline Tokyo Bay & 18.0 & 61.06 & 0.262 & 16.00 & -0.379 \\
\hline Seto Inland Sea & 17.5 & 55.46 & 0.295 & 16.35 & -0.383 \\
\hline Ariake Bay & 20.5 & 76.44 & 0.403 & 23.10 & -0.335 \\
\hline
\end{tabular}


Fig. 5. Phacosoma japonicum. Plot of the number of microincrements within an annual increment versus annual increment number for samples examined. Sample mean and range of standard deviation indicated for each sample
Fig. 6. Phacosoma japonicum. Plot of the mean microincrement width within an annual increment versus annual increment number for samples examined. Sample mean and the range of standard deviation indicated for each sample
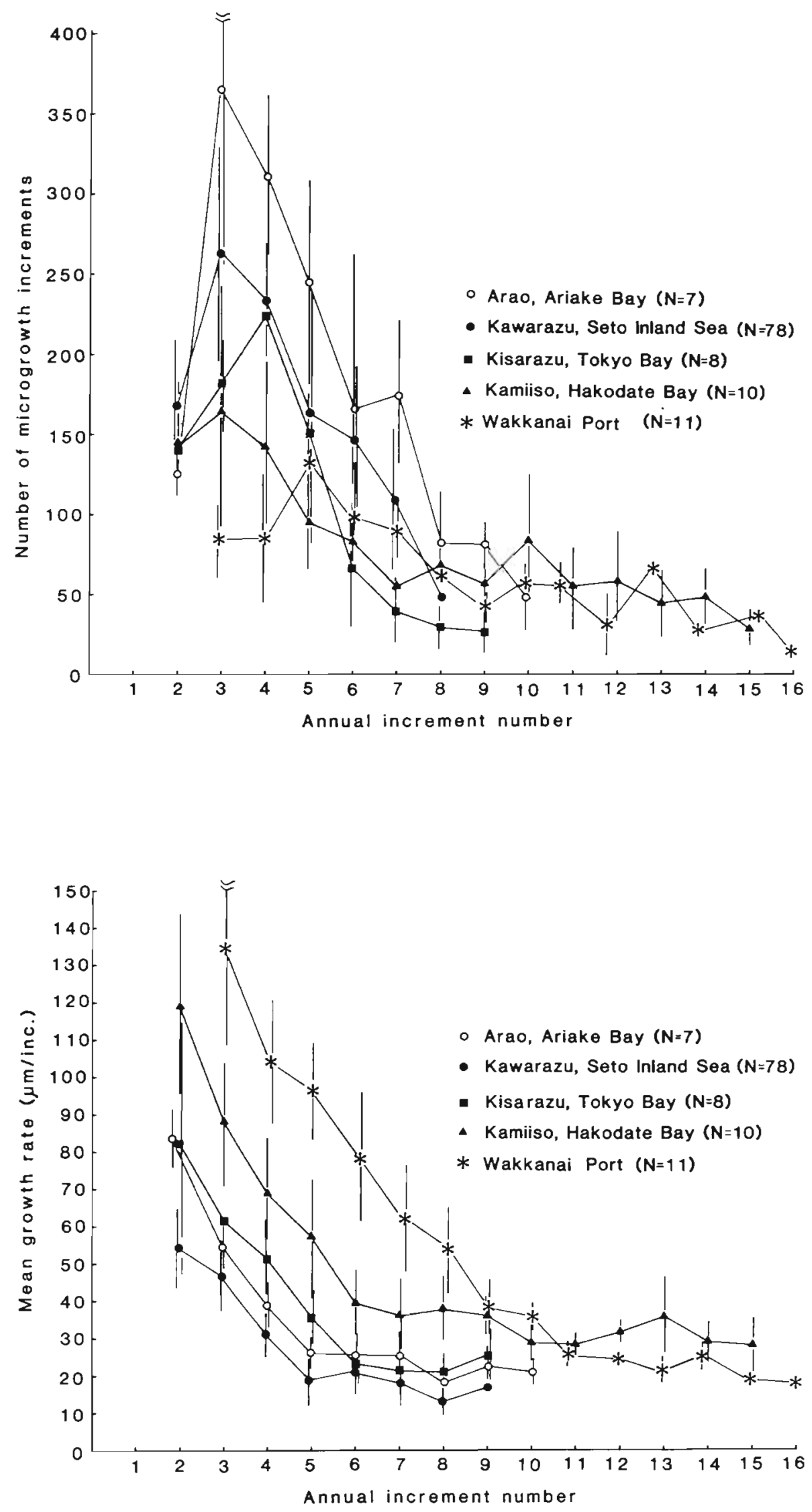

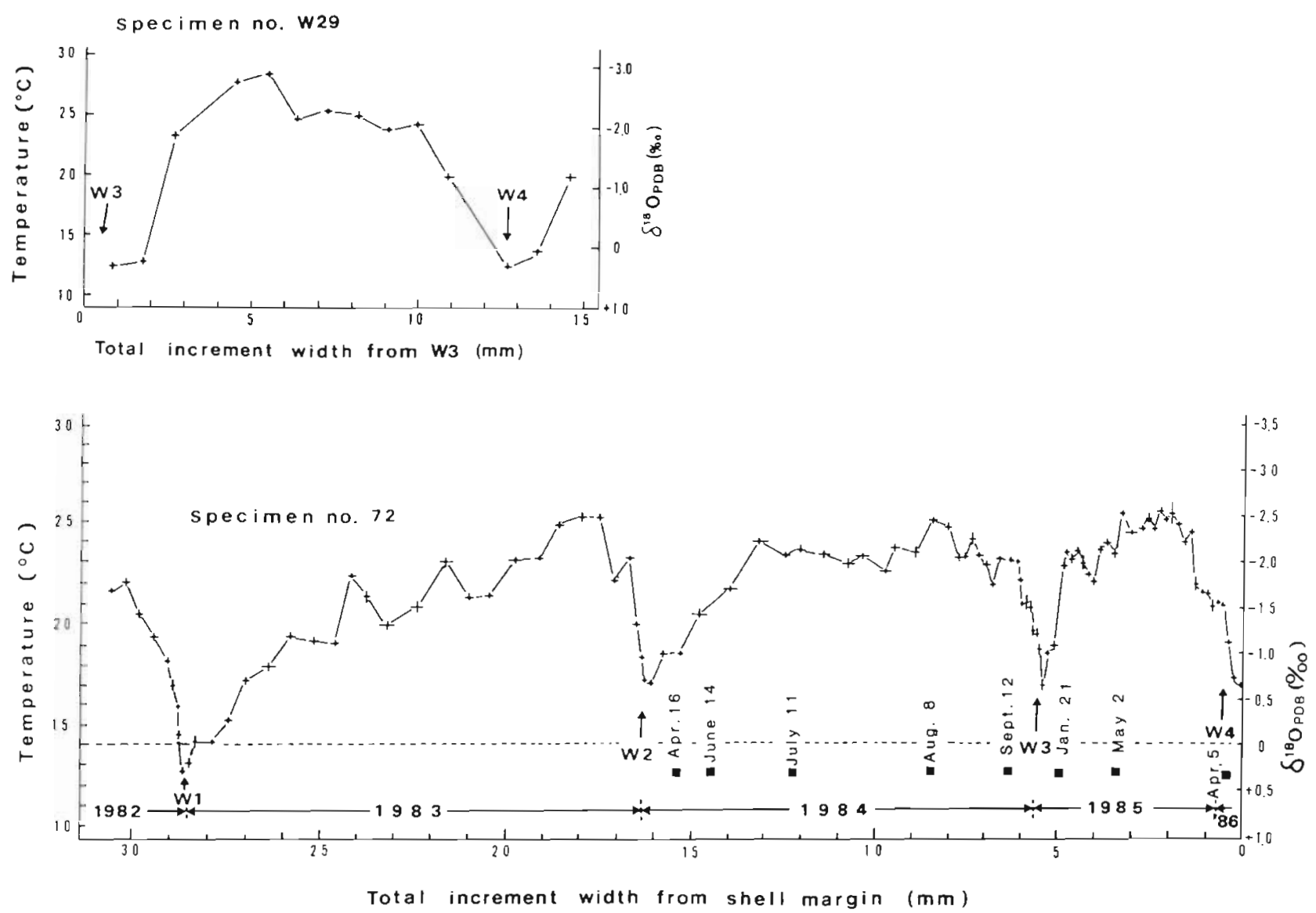

Fig. 7. Phacosoma japonicum. Oxygen isotopic profiles and corresponding temperatures in 2 specimens from Wakkanai Port and Kawarazu Shore (Seto Inland Sea). Sclerochronological data are added for the Kawarazu specimen. Wi $(=W 1-W 4)$ means $i$-th winter growth cessation mark

$\delta^{18} \mathrm{O}$ cycle is discernible in the 2 profiles, and the portions with highest $\delta^{18} \mathrm{O}$ value are located near the winter growth cessation mark. It is well known that ${ }^{18} \mathrm{O} /{ }^{16} \mathrm{O}$ ratios of the calcified tissue in an aquatic animal are changeable with water temperature and salinity of the habitat (Dodd \& Stanton 1981). Annual fluctuation of salinity is minimal at least for the sampling station of the Kawarazu Shore (31 to $33 \%$ ), and this suggests the cyclic patterns in the $\delta^{18} \mathrm{O}$ profiles mostly reflect the annual fluctuation of water temperature

Growth history of the Kawarazu specimen was traced for more than 2 yr by the mark-and-recovery method, together with the record of temperature and salinity at the planting site (Tanabe 1988). The plot of $\delta^{18} \mathrm{O}$ ratios at the 4 portions of the specimen formed during the season of rapid shell growth versus water temperatures of corresponding dates provides a linear relationship between the isotopic ratio and the water temperature (Fig. 8). The temperature scale shown in $\delta^{18} \mathrm{O}$ profiles of the Kawarazu and Wakkanai specimens (Fig. 7) was estimated from the linear relationship. In both specimens, temperatures calculated from $0^{18} \mathrm{O}$ ratios in the central portion of annual increments correlate well with the water temperatures of the summer season. The lowest temperatures detected near the winter growth cessation marks of the 2 specimens (ca $12^{\circ} \mathrm{C}$ ) are, by contrast, higher by 5 to $10^{\circ} \mathrm{C}$ than the winter water temperatures of the sampling locations.

\section{DISCUSSION}

Phacosoma japonicum from the Japanese coast shows latitudinal trends in the growth parameters of von Bertalanffy equations and accretionary patterns of microincrements. Especially, high negative correlation between rate of growth deceleration and mean annual temperatures (Table 1) suggests a dependence of growth on temperature. Based on the samples examined, northern individuals generaljy possess more numerous annual increments than the southern ones. suggesting a longer life span in the former (Fig.4). However, exact longevity cannot be determined from annual increment counting, because large animals 


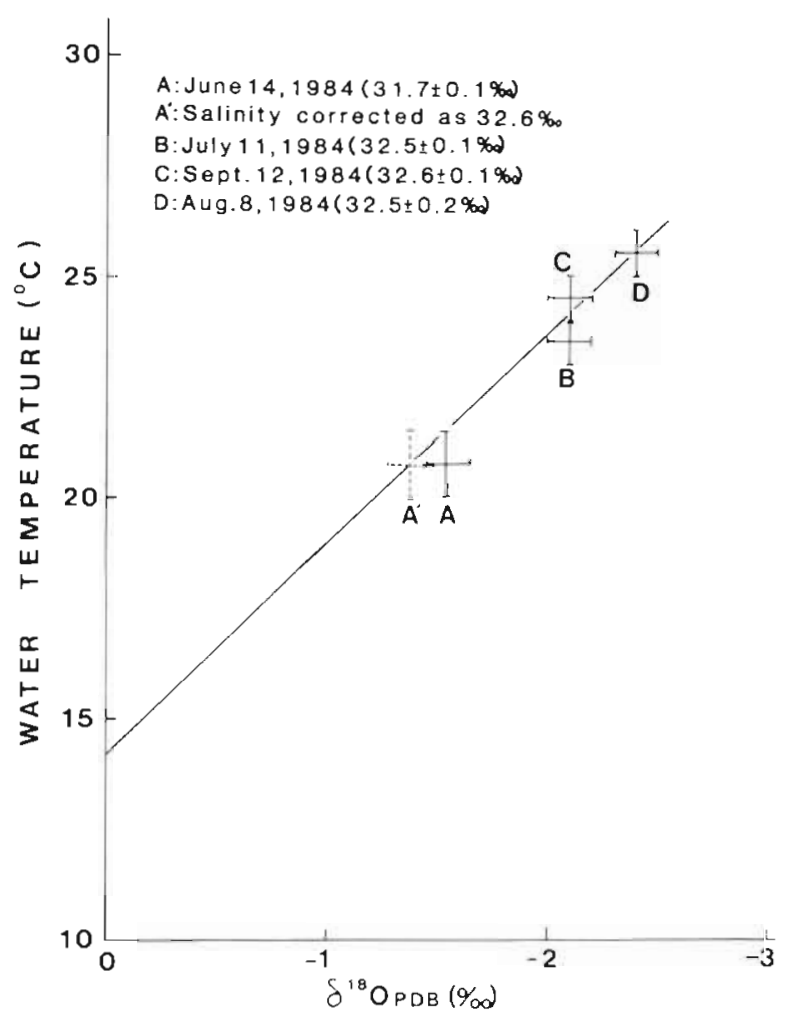

Fig. 8. Phacosoma japonicum. Linear relationship between $\delta^{18} \mathrm{O}$ ratios at the 4 portions of the Kawarazu specimen and water temperatures of corresponding dates. Vertical and horizontal bars indicate ranges of errors in measurements. Regression line by the least squares fit

inhabiting the Kawarazu Shore can survive for more than several years after completion of shell growth (Tanabe 1988). Therefore, the above hypothesis must be tested by other methods such as long-term growth analysis of marked individuals.

Reductions of growth rate in the colder areas of distribution (higher latitudes) have been observed in many marine bivalves hitherto investigated. Furthermore, longer life span and shorter growing seasons in northern individuals than southern ones has been suggested in Siliqua patula (Weymouth \& McMillin 1931). Macoma balthica (Gilbert 1973, Bachelet 1980) and Protothaca staminea (Harrington 1987). Most previous authors also regarded temperature as a dominant factor affecting the difference in growth patterns of marine bivalves over a wide geographic range (e.g. Appeldoorn 1983, Beukema \& Meehan 1985).

It has been generally accepted that acceretionary patterns of microincrements reflect the seasonal variation in shell growth rate (Rhoads \& Pannella 1970, Lutz \& Rhoads 1980, Jones 1985). Annual cycles in oxygen isotope ratios and corresponding temperatures were detected in the shells of many bivalve species (e.g.
Spisula solidissima, Jones et al. 1983; Placopecten magellanicus, Krantz et al. 1984), but little was investigated about the exact relationship between the length of growing seasons and temperature from the sclerochronological point of view.

The present study on Phacosoma japonicum strongly suggests slow and continuous winter growth for the southernmost individuals from Ariake Bay, judging from the narrow and crowded microincrements near the end of an annual increment without a growth cessation mark (Fig. 3E). In contrast, the presence of a clear growth cessation mark at the boundary between 2 adjoining annual increments in specimens from other locations (Figs. 3A to D) indicates a partial dissolution of microincrements at the ventral shell margin during winter. The degree of disagreement between temperatures estimated from $\delta^{18} \mathrm{O}$ ratios near the winter growth cessation marks and the sea-surface temperatures of habitat for the Wakkanai specimen is more conspicuous than that for the Kawarazu specimen (Fig. 7). Furthermore, the number of annually formed microincrements at a given age tends to decrease with increasing latitude (Fig. 5). These lines of evidence strongly suggest a latitudinal decrease in the length of growing seasons in this species. A similar idea was suggested by Harrington (1987) for the eastern Pacific Protothaca staminea, based on the latitudinal decrease

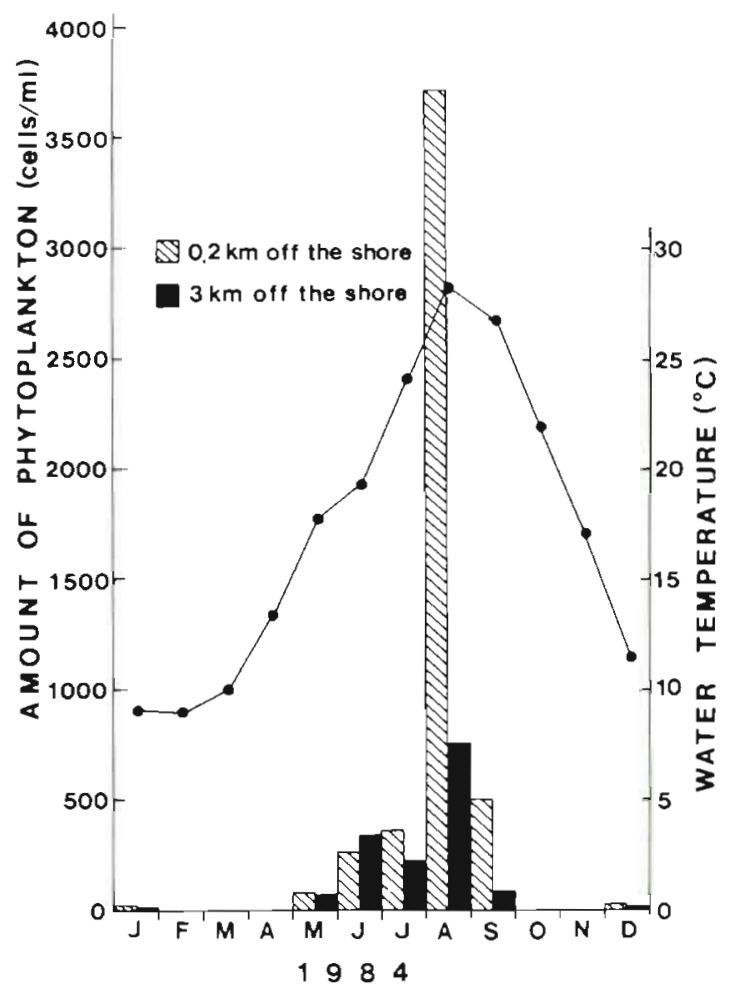

Fig. 9. Seasonal variation in phytoplankton abundance in the water of the Kawarazu Shore, Seto Inland Sea 
in the number of microincrements within the first annual increment. Harrington (1987) used external growth bands for age determination, but did not show sufficient documentation for their annual origin.

In the population of the Seto Inland Sea, remarkable shell growth occurs in a limited interval between April and September (Tanabe 1988). Furthermore, sclerochronology of a single shell (no. 72, same specimen used in this study) revealed especially high rates of microincrement growth (1.2 to 1.7 increments $\left.\mathrm{d}^{-1}\right)$ during June to September (Tanabe 1988). The above seasonal pattern of microincrement growth correlates well with that of phytoplankton abundance in the Kawarazu Shore (Fig. 9). The range of temperatures obtained from oxygen isotope ratios in the second annual increment (= 2 yr-old stage) of the Kawarazu specimen $\left(13\right.$ to $\left.25^{\circ} \mathrm{C}\right)$ (Fig. 7) is compared with that of sea-water temperatures during March to November. Meanwhile, the oxygen isotopic temperatures in the fourth annual increment of the Wakkanai specimen $\left(13\right.$ to $\left.28^{\circ} \mathrm{C}\right)$ show a close correspondence to the water temperatures between June and October at the sampling station.

In conclusion, latitudinal variation of growth patterns observed in Phacosoma japonicum from the Japanese coast results mainly from the difference in the length of the growing season among local populations, depending on both temperature and trophic resource seasonality.

Acknowledgements. We thank the staffs of the Ehime Prefectural fisheries experiment station in Toyo and of the marine biological station of Hokkaido University of Education in Hakodate for providing us with oceanographic and plankton data of the study areas; Tomoki Kase, Yasuo Kondo, Toshio Takagi, Akihiko Suzuki and Takashi Katsuta for their help in collecting samples; and Kazuo Yamamoto for providing assistance in isotope analysis. Douglas Jones and Itaru Hayami gave helpful comments and suggestions for improvement of this paper. This work was supported by the Science Research Fund of the Japanese Government (no. 61480028 in $1986-1987$; no. 63540622 in 1988)

\section{LITERATURE CITED}

Appeldoorn, R. S. (1983). Variation in the growth rate of $M y a$ arenaria and its relationship to the environment as analyzed through principal components analysis and the parameter of the von Bertalanffy equation. Fish. Buil. U.S. 81: 75-84

Bachelet, G. (1980). Growth and recruitment of the tellinid bivalve Macoma balthica at the southern limit of its geographical distribution, the Gironde Estuary (SW France). Mar Biol. 59: 105-117

Beukema, J. J., Meehan, B. W. (1985). Latitudinal variation in linear growth and other shell characteristics of Macoma balthica. Mar Biol. 90: 27-33

Dodd, J. R. Stanton, R. J Jr (1981). Paleoecology, concepts and applications. Wiley, New York

Epstein, S., Buchshaum, R., Lowenstam, H. A., Urey, H. C. (1953). Revised carbonate-water isotopic temperature scale. Geol. Soc. A.m. BuIl, 64: 1315-1326
Gallucci, V. F., Quinn II, T. J. (1979). Reparameterizing, fitting, and testing of a simple growth model. Trans. Am. Fish. Soc. 108: $14-25$

Gilbert, M. A. (1973). Growth rate, longevity and maximum size of Macoma balthica (L.). Biol. Bull. mar biol. Lab., Woods Hole 45: 119-126

Habe, T. (1977). Systematics of mollusca in Japan: Bivalvia and Scaphopoda. Hokuryukan Book Co., Tokyo

Hall, C. A. Jr, Dollase, W. A., Corbato, C. E. (1974). Shell growth in Tivela stultorum (Mawe, 1823) and Callista chione (Linnaeus, 1758) (Bivalvia): annual periodicity, latitudinal differences, and diminuation with age. Palaeogeogr. Palaeoclimatol. Palaeoecol. 15: 33-61

Hallam, A. (1967). The interpretation of size-frequency distributions in molluscan death assemblages. Palaeontology 10: $25-42$

Harrington, R. J. (1987). Skeletal growth histories of Protothaca staminea (Conrad) and Protothaca grata (Say) throughout their geographic ranges, northeastern Pacific. Veliger 30: $148-158$

Japan Meteorological Agency (1986). The results of marine meteorological and oceanographical observations, no. 77 (Jan.-Dec. 1985). The Japan Meteorological Agency, Tokyo

Jones, D.S. (1980). Annual cycle of shell growth increment formation in two continental shelf bivalves and its paleoecologic significance. Paleobiology 6: 331-340

Jones, D. S. (1985). Growth increments and geochemical variations in the molluscan shell. In: Broadhead, T.W. (ed.) Mollusks. Univ. Tennessee, Dept of Geol. Sci., Studies in Geol. 13, p. 72-87

Jones, D. S., Thompson, I., Ambrose W. (1978). Age and growth rate determinations for the Atlantic surf clam Spisula solidissima (Bivalvia, Mactraceae), based on internal growth lines in shell cross-sections. Mar. Biol. 47: 63-70

Jones, D.S., Williams, D. F., Arthur, M. A. (1983). Growth history and ecology of the Atlantic surf clam, Spisula solidissima (Dillwyn), as revealed by stable isotopes and annual shell increments. J. exp. mar. Biol. Ecol. 73: 225-242

Kranz, D. E., Jones, D. L., Williams, D. F. (1984). Growth rates of the sea scallop, Placopecten magellanicus, determined from the ${ }^{18} \mathrm{O} /{ }^{16} \mathrm{O}$ record in shell calcite. Biol. Bull. mar. biol. Lab., Woods Hole 167: 186-199

Lutz, R. A., Rhoads, D. C. (1980). Growth patterns within the molluscan shell. An overview. In: Rhoads, D. C., Lutz, R. (eds.) Skeletal growth of aquatic organisms. Plenum Press, New York, p. 203-254

Mason, J. (1957). The age and growth of the scallop, Pecten maximus (L.), in Manx waters. J. mar. biol. Ass. U. K. 36: $473-492$

Rhoads, D. C., Pannella, G. (1970). The use of molluscan shell growth patterns in ecology and paleoecology. Lethaia 3 : 143-161

Seed, R., Brown, R. A. (1978). Growth as a strategy for survival in two marine bivalves. Cerastoderma edule and Modiolus modiolus. J. Anim. Ecol. 47 283-292

Tanabe, K. (1988). Age and growth rate determinations of an intertidal bivalve, Phacosoma japonicum, using internal shell increments. Lethaia 21 (in press)

von Bertalanffy, L. (1938). A quantitative theory of organic growth inquiries on growth laws. II. Human Biol. 10: $181-213$

Weymouth, F.W., McMillin, H. C. (1931) The relative growth and mortality of the Pacific razor clam (Siliqua patula Dixon) and their bearing on the commercial fishery. Bull. U.S. Bur Fish. 46: 543-567 